\title{
Isolated Adrenocorticotropic Hormone Deficiency and Severe Hypercalcemia After Destructive Thyroiditis in a Patient on Nivolumab Therapy With a Malignant Melanoma
}

\author{
Kohzo Takebayashia, b, Atsushi Ujiie ${ }^{\mathrm{a}}$, Mio Kubo ${ }^{\mathrm{a}}$, Sho Furukawa ${ }^{\mathrm{a}}$, Mototaka Yamauchi ${ }^{\mathrm{a}}$, \\ Hiroyuki Shinozakia, Tatsuhiko Suzuki ${ }^{a}$, Rika Naruse ${ }^{a}$, Kenji Hara ${ }^{a}$, \\ Takafumi Tsuchiya ${ }^{a}$, Toshihiko Inukai ${ }^{a}$
}

\begin{abstract}
We describe a 58-year-old man with a malignant melanoma metastasis to the liver. After initiation of nivolumab therapy, he developed destructive thyroiditis and subsequently simultaneous isolated adrenocorticotropic hormone (ACTH) deficiency and severe hypercalcemia. Although isolated ACTH deficiency and hypercalcemia due to nivolumab therapy are both rare occurrences, these conditions can often cause a severe clinical course accompanied by a disturbance of consciousness. Therefore, clinicians should pay attention to these possible side effects of nivolumab if the patients have clinical symptoms, such as fatigue and a disturbance of consciousness.
\end{abstract}

Keywords: Nivolumab; Destructive thyroiditis; Isolated ACTH deficiency; Hypercalcemia

\section{Introduction}

Immune checkpoint inhibitors, a new class of drugs for cancer treatment, have received considerable attention because of their good efficacy based on unique immunological mechanisms [1]. These inhibitors have now been approved in many countries for the treatment of various cancers [2]. Nivolumab, a human immunoglobulin G4 (IgG4) antibody, is a representative immune checkpoint inhibitor. It binds to programmed cell death 1 (PD-1) on active T cells and blocks the binding of PD-1 to either the PD-ligand 1 (PD-L1) or PD-L2 expressed on the surface of cancers cells $[3,4]$. In Japan, nivolumab has been approved currently for the treatment for some diseases states of malignant melanoma, renal cell carcinoma, Hodgkin's lym-

Manuscript submitted November 8, 2017, accepted November 20, 2017

aDepartment of Internal Medicine, Dokkyo Medical University Koshigaya Hospital, Koshigaya, Saitama, Japan

${ }^{b}$ Corresponding Author: Kohzo Takebayashi, Department of Internal Medicine, Dokkyo Medical University Koshigaya Hospital, 2-1-50, Minami-Koshigaya, Koshigaya, Saitama 343-8555, Japan. Email: takeb@gmail.plala.or.jp

doi: https://doi.org/10.14740/jocmr3257w phoma, head and neck cancer, non-small cell lung carcinoma, and gastric cancer. Importantly, immune checkpoint inhibitors, including nivolumab, can cause various immune-related adverse events (irAEs), such as dermatitis, colitis, hepatitis, and endocrine irAEs [1, 2]. Endocrine irAEs include thyroiditis, hyper- and hypothyroidism, hypophysitis, and type 1 diabetes $[1,2]$. Clinicians need to pay particular attention to the endocrine irAEs because of their varied clinical courses, and the effects are often irreversible [5]. Here, we report the first case of a patient who received nivolumab therapy for a melanoma metastasis to the liver and developed simultaneous onset of isolated adrenocorticotropic hormone (ACTH) deficiency and severe hypercalcemia after destructive thyroiditis.

\section{Case Report}

A 58-year-old man, who have developed type 2 diabetes and hypertension and was receiving sitagliptin for the former and atenolol for the latter for the last 10 years, was diagnosed with malignant melanoma of the left eyeball choroid in December 2012. After an ophthalmectomy, he had regular medical followups for malignant melanoma in the Department of Ophthalmology in our hospital. In March 2016, a liver metastasis was found by systemic computer tomography (CT), and he was referred to the Department of Dermatology. He was given nivolumab injection therapy ( $3 \mathrm{mg} / \mathrm{kg}$ per 2 weeks) from April 2016. Although a slight enlargement of the liver metastasis on CT was noted in June 2016, subsequent follow-up CTs did not show the apparent enlargement, and therefore the nivolumab treatment was continued. In mid-August 2016, moderate hyperthyroidism was found in a blood test, and the patient was referred to our department (endocrinology and diabetes). On his first visit to our department, his height and body weight were $160 \mathrm{~cm}$ and 60.5 $\mathrm{kg}$, respectively. He was fully conscious, and his blood pressure and pulse rate were $120 / 60 \mathrm{~mm} \mathrm{Hg}$ and $82 / \mathrm{min}$, respectively. No apparent chest, abdominal, and neurological findings were observed. His blood test demonstrated moderate hyperthyroidism: free $\mathrm{T}_{4}\left(\mathrm{FT}_{4}\right) 2.43 \mathrm{ng} / \mathrm{dL}$ (normal values: $0.97-1.79 \mathrm{ng} /$ $\mathrm{dL}$ ), free $\mathrm{T}_{3}\left(\mathrm{FT}_{3}\right) 6.94 \mathrm{pg} / \mathrm{mL}$ (normal values: $2.47-4.34 \mathrm{pg} /$ $\mathrm{mL}$ ), and TSH $<0.3 \mu \mathrm{U} / \mathrm{mL}$ (normal values: $0.0-3.0 \mu \mathrm{U} / \mathrm{mL}$ ). In addition, the anti-thyroglobulin antibody ( $\mathrm{TgAb}$ ) was elevat- 
Table 1. Hematological and Blood Chemistry Tests (Mid December 2016)

\begin{tabular}{|c|c|}
\hline \multicolumn{2}{|l|}{ Hematological } \\
\hline WBC & $7,800 / \mu \mathrm{L}$ \\
\hline $\mathrm{RBC}$ & $416 \times 10^{4} / \mu \mathrm{L}$ \\
\hline $\mathrm{Hb}$ & $12.2 \mathrm{~g} / \mathrm{dL}$ \\
\hline $\mathrm{Ht}$ & $37.3 \%$ \\
\hline Plt & $18.0 \times 10^{4} / \mu \mathrm{L}$ \\
\hline \multicolumn{2}{|l|}{ Urinalysis } \\
\hline Blood & $(-)$ \\
\hline Protein & $(-)$ \\
\hline Glucose & $(3+)$ \\
\hline \multicolumn{2}{|c|}{ Blood chemistry } \\
\hline TP & $6.8 \mathrm{~g} / \mathrm{dL}$ \\
\hline Alb & $3.84 \mathrm{~g} / \mathrm{dL}$ \\
\hline AST & $144 \mathrm{U} / \mathrm{L}$ \\
\hline ALT & $43 \mathrm{U} / \mathrm{L}$ \\
\hline ALP & $102 \mathrm{U} / \mathrm{L}$ \\
\hline LDH & $198 \mathrm{U} / \mathrm{L}$ \\
\hline GGT & $19 \mathrm{U} / \mathrm{L}$ \\
\hline T-Bil & $1.65 \mathrm{mg} / \mathrm{dL}$ \\
\hline BUN & $44 \mathrm{mg} / \mathrm{dL}$ \\
\hline $\mathrm{Cr}$ & $2.11 \mathrm{mg} / \mathrm{dL}$ \\
\hline $\mathrm{Na}$ & $136 \mathrm{mEq} / \mathrm{L}$ \\
\hline $\mathrm{K}$ & $5.3 \mathrm{mEq} / \mathrm{L}$ \\
\hline $\mathrm{Cl}$ & $97 \mathrm{mEq} / \mathrm{L}$ \\
\hline $\mathrm{P}$ & $4.6 \mathrm{mg} / \mathrm{dL}$ \\
\hline $\mathrm{Ca}$ & $14.2 \mathrm{mg} / \mathrm{dL}$ (corrected by albumin 14.36 ) \\
\hline FPG & $139 \mathrm{mg} / \mathrm{dL}$ \\
\hline HbAlc & $5.7 \%$ \\
\hline $\mathrm{FT}_{4}$ & $1.00 \mathrm{ng} / \mathrm{dL}$ \\
\hline $\mathrm{FT}_{3}$ & $2.76 \mathrm{pg} / \mathrm{mL}$ \\
\hline TSH & $15.73 \mu \mathrm{U} / \mathrm{mL}$ \\
\hline CRP & $20.73 \mathrm{mg} / \mathrm{dL}$ \\
\hline
\end{tabular}

WBC: white blood cell; RBC: red blood cell; Hb: hemoglobin; Plt: platelet; TP: total protein; Alb: albumin; AST: aspartate transaminase; ALT: alanine transaminase; ALP: alkaline phosphatase; LDH: lactate dehydrogenase; GGT: gamma-glutamyl transpeptidase; T-Bil: total bilirubin; BUN: urea nitrogen; Cr: creatinine; Na: sodium; K: potassium; Cl: chlorine; P: phosphoric; Ca: calcium; FPG: fasting plasma glucose; HbA1c: hemoglobin $\mathrm{A} 1 \mathrm{c} ; \mathrm{FT}_{4}$ : free $\mathrm{T}_{4} ; \mathrm{FT}_{3}$ : free $\mathrm{T}_{3}$; $\mathrm{TSH}$ : thyroid-stimulating hormone; CRP: C-reactive protein.

ed, whereas the anti-thyroid peroxidase antibody (TPOAb) was in the normal range: $212 \mathrm{IU} / \mathrm{mL}$ (normal values: 0 - $28 \mathrm{IU} / \mathrm{mL}$ ) for the former and $6 \mathrm{IU} / \mathrm{mL}$ (normal values: 0 - $16 \mathrm{IU} / \mathrm{mL}$ ) for the latter. Furthermore, the anti-thyroid-stimulating hormone receptor antibody (TRAb) was negative: $<0.005 \mathrm{IU} / \mathrm{L}$ (normal value: 0 - $2 \mathrm{IU} / \mathrm{L}$ ). Because of the negative findings for TRAb, destructive thyroiditis was the most plausible diagnosis, and he was followed up with only regular check-ups without addition of any anti-thyroid drugs. Thereafter, his thyroid-related hormone values were almost normal in mid-October $2016\left(\mathrm{FT}_{4}\right.$ : $1.03 \mathrm{ng} / \mathrm{dL}, \mathrm{FT}_{3} 4.20 \mathrm{pg} / \mathrm{mL}$, TSH $0.013 \mu \mathrm{U} / \mathrm{mL}$ ). In mid-November 2016, he had fatigue, and a sensation of weakness in his systemic muscles. Because of the possible onset of myasthenia gravis, a known side effect of nivolumab therapy $[6,7]$, he was referred to the Neurology Department. However, based on the lack of both eye symptoms and clinically apparent muscle weakness in his extremities, and negative findings of antiacetylcholine receptor antibody (AChRAb) $(<0.2 \mathrm{nmol} / \mathrm{L}$, normal values: $<0.2 \mathrm{nmol} / \mathrm{L}$ ), the neurologist determined that the patient did not have myasthenia gravis. In addition, the patient did not have myositis based on normal creatine phosphokinase (CPK) levels in the blood. Administration of nivolumab was continued until mid-November 2016 and was subsequently discontinued. In mid-December 2016, mild hypothyroidism was noted by a blood test $\left(\mathrm{FT}_{4} 0.89 \mathrm{ng} / \mathrm{dL}, \mathrm{FT}_{3} 3.61 \mathrm{pg} / \mathrm{mL}, \mathrm{TSH}\right.$ $14.17 \mu \mathrm{U} / \mathrm{mL}$ ), and therefore $25 \mu \mathrm{g}$ /day levothyroxine was started immediately. After 1 week, the patient again reported fatigue, a systemic sensation of weakness, and appetite loss. Furthermore, his family noted that he could not articulate well. He was transferred to our hospital by ambulance and was immediately hospitalized because of either a possible brain metastasis or cerebral bleeding. On admission, he was lethargic but his responses to question were basically good. His temperature, blood pressure, and pulse rate were $37.9^{\circ} \mathrm{C}, 114 / 78 \mathrm{~mm} \mathrm{Hg}$, and $60 / \mathrm{min}$, respectively. There were no chest, abdominal, or neurological findings on physical examination. No abnormality was found in his brain CT. However, his blood test showed remarkably elevated calcium $(\mathrm{Ca})$ levels $(\mathrm{Ca}$ corrected by albumin: $14.36 \mathrm{mg} / \mathrm{dL}$ (normal values of Ca: 9.0 - $10.2 \mathrm{mg} / \mathrm{dL}$ )) (Table 1), and therefore treatment for hypercalcemia with 4 $\mathrm{mg}$ /day zoledronate by intravenous infusion, $40 \mathrm{mg}$ /day furosemide by intravenous infusion, 40 units L-calcitonin by intramuscular injection twice a day, and fluid therapy with normal saline were started immediately. With the treatment, the serum Ca levels improved relatively rapidly (corrected Ca: $13.36 \mathrm{mg} /$ $\mathrm{dL}$ at 1 day (next day), $10.52 \mathrm{mg} / \mathrm{dL}$ at 3 days, and $9.57 \mathrm{mg} /$ $\mathrm{dL}$ at 6 days after onset day), and the improvement in both the fatigue and sensation of weakness and the normalization of consciousness correlated with the changes in the serum $\mathrm{Ca}$ levels. Intact parathyroid hormone (PTH), PTH-related protein (PTHrP), and $1.25(\mathrm{OH}) 2$ vitamin $\mathrm{D}$, which were measured to investigate the cause of elevated $\mathrm{Ca}$ in sera, showed the values of $12 \mathrm{pg} / \mathrm{mL}$ (normal values: $10-65 \mathrm{pg} / \mathrm{mL}$ ),$<1.0 \mathrm{pmol} / \mathrm{L}$ (normal values $<1.0 \mathrm{pmol} / \mathrm{L}$ ), and $7.7 \mathrm{pg} / \mathrm{mL}$ (normal values: $20-60 \mathrm{pg} / \mathrm{mL}$ ), respectively. Bone scintigraphy showed only one possible metastasis in the left rib (Fig. 1). Because it is reported that nivolumab can cause not only primary adrenal failure but also secondary one due to isolated ACTH deficiency although rare, and because adrenal failure can cause a disturbance of consciousness, which was confirmed in our previous case [8], we performed tests for corticotropin-releasing hormone (CRH)-, thyrotropin-releasing hormone (TRH)-, and luteinizing hormone-releasing hormone (LHRH)-stimulation. These tests revealed that the patient developed isolated ACTH deficiency (Table 2), while a brain magnetic resonance imag- 


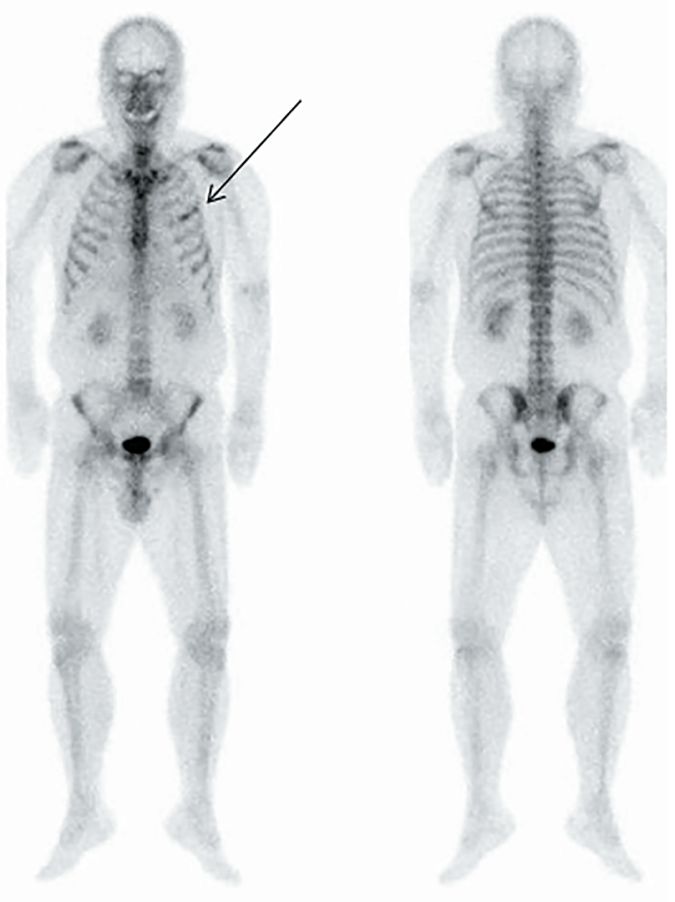

Figure 1. Bone scintigraphy on the day when the patient developed a disturbance of consciousness (mid December 2016). Front (left) and back (right) views are shown. An arrow shows the portion of left rib with a possible malignant melanoma metastasis.

ing (MRI) showed a normal finding on the pituitary. Hydrocortisone (15 mg morning, $5 \mathrm{mg}$ evening/day) was immediately given to the patient. On admission, elevated C-reactive protein (CRP) level was also noted, and therefore a possible bacterial infection was suspected but not apparent. After antibiotic treatment ( $0.5 \mathrm{~g}$ /day meropenem intravenous injection), the CRP levels relatively rapidly improved to normal. Because of the tendency for enlargement noted on an abdominal CT performed on December 2016, nivolumab was replaced with dacarbazine (DTIC) treatment due to concerns of a liver metastasis.

\section{Discussion}

Our patient developed hyperthyroidism approximately 4 months after initiation of nivolumab therapy. Such a complication was found previously with thyroid hormone dysfunction after nivolumab therapy for a median time of $1.5-2.9$ months [9]. We speculate that the hyperthyroidism in our case was probably due to destructive thyroiditis and not due to the onset of Graves' disease because of the negative TRAb. Further support of this conclusion was that the thyroid hormones levels improved after observation without the need for antithyroid drugs. Interestingly, the $\mathrm{TgAb}$ was positive. We speculate that this may have been due to the possible elevation of thyroglobulin due to the destructive thyroiditis, although we did not measure the serum thyroglobulin levels at that time.

In our case, 3 months after thyroid hormone dysfunction
Table 2. CRH, TRH and LHRH Loading Tests

\begin{tabular}{|c|c|}
\hline \multicolumn{2}{|l|}{ ACTH } \\
\hline $0 \mathrm{~min}$ & $<2.0 \mathrm{pg} / \mathrm{mL}$ \\
\hline $30 \mathrm{~min}$ & $<2.0 \mathrm{pg} / \mathrm{mL}$ \\
\hline $60 \mathrm{~min}$ & $<2.0 \mathrm{pg} / \mathrm{mL}$ \\
\hline \multicolumn{2}{|l|}{ Cortisol } \\
\hline $0 \mathrm{~min}$ & $0.34 \mu \mathrm{g} / \mathrm{dL}$ \\
\hline $60 \mathrm{~min}$ & $0.35 \mu \mathrm{g} / \mathrm{dL}$ \\
\hline $90 \mathrm{~min}$ & $0.36 \mu \mathrm{g} / \mathrm{dL}$ \\
\hline \multicolumn{2}{|l|}{$\mathrm{LH}$} \\
\hline $0 \mathrm{~min}$ & $13.7 \mathrm{mIU} / \mathrm{mL}$ \\
\hline $30 \mathrm{~min}$ & $41.2 \mathrm{mIU} / \mathrm{mL}$ \\
\hline $60 \mathrm{~min}$ & $38.7 \mathrm{mIU} / \mathrm{mL}$ \\
\hline \multicolumn{2}{|l|}{ FSH } \\
\hline $0 \mathrm{~min}$ & $9.8 \mathrm{mIU} / \mathrm{mL}$ \\
\hline $60 \mathrm{~min}$ & $13.6 \mathrm{mIU} / \mathrm{mL}$ \\
\hline $90 \mathrm{~min}$ & $13.0 \mathrm{mIU} / \mathrm{mL}$ \\
\hline \multicolumn{2}{|l|}{$\mathrm{TSH}$} \\
\hline $0 \mathrm{~min}$ & $26.630 \mu \mathrm{U} / \mathrm{mL}$ \\
\hline $30 \mathrm{~min}$ & $95.210 \mu \mathrm{U} / \mathrm{mL}$ \\
\hline $60 \mathrm{~min}$ & $77.660 \mu \mathrm{U} / \mathrm{mL}$ \\
\hline \multicolumn{2}{|l|}{ PRL } \\
\hline $0 \mathrm{~min}$ & $3.9 \mathrm{ng} / \mathrm{mL}$ \\
\hline $30 \mathrm{~min}$ & $26.8 \mathrm{ng} / \mathrm{mL}$ \\
\hline $60 \mathrm{~min}$ & $15.6 \mathrm{ng} / \mathrm{mL}$ \\
\hline
\end{tabular}

$\mathrm{CRH}$ : corticotropin-releasing hormone; TRH: thyrotropin-releasing hormone; LHRH: luteinizing hormone-releasing hormone; ACTH: adrenocorticotropic hormone; TSH: thyroid-stimulating hormone; LH: luteinizing hormone; PRL: prolactin; FSH: follicle-stimulating hormone. $\mathrm{CRH}$ $100 \mu \mathrm{g}$, TRH $0.5 \mathrm{mg}$, LHRH $0.1 \mathrm{mg}$ with $10 \mathrm{~mL}$ normal saline was injected intravenously under rest spine state.

(i.e., hyperthyroidism), and about 10 days after the final administration of nivolumab, the patient noted both fatigue and a sensation of weakness. Myasthenia gravis was considered to be negative based on the clinical findings and negative AChRAb. Importantly, 1 month after the final nivolumab treatment, the patient developed mild impairment of consciousness expressed as lethargy with fatigue and a sensation of weakness, although it is unclear whether the causes of the previous symptoms were associated with the ones at this time. The $\mathrm{CRH}, \mathrm{TRH}$, and LHRH stimulation tests on the day following the symptom onset revealed that he also had an isolated ACTH deficiency. Compared with ipilimumab (other type of immune checkpoint inhibitors), which is an antibody for cytotoxic T lymphocyte antigen-4 (CTLA-4), nivolumab-induced isolated ACTH deficiency is considered to be generally rare [10], although recently some reports demonstrated nivolumabinduced isolated ACTH deficiency especially in Japan [11-13]. At the present time, the detailed mechanisms of nivolumabinduced isolated ACTH deficiency remain unclear because 
the expression of PD-1/PD-L1 in the pituitary, unlike that of CTLA-4, is not evident [14].

At approximately the same time, the patient developed severe hypercalcemia. In this case, the onset of both hyperparathyroidism and hypervitaminosis $\mathrm{D}$ was not likely due to the serum levels of PTH and $1.25(\mathrm{OH}) 2$ vitamin D as these levels were normal and low, respectively. Furthermore, PTHrP-related hypercalcemia was also considered to be negative because of the negative serum PTHrP level. In addition, bone metastasis as the cause of hypercalcemia was not likely since only one rib metastasis was found by bone scintigraphy. Interestingly, there is a report of hypercalcemia accompanied by isolated ACTH deficiency [15], although the detail mechanism is unknown [16]. Furthermore, hypercalcemia associated with nivolumab treatment has also been previously reported $[17,18]$, although it is very rare, and the detailed mechanisms are unclear. In the randomized open-label phase 3 trial for nivolumab therapy for patients with recurrent head and neck squamous cell carcinoma, grade 3-4 and grade 5 adverse events of hypercalcemia were observed in one patient each in the nivolumab treatment group $(n=236)$, whereas the occurrence of grade 3-4 and grade 5 adverse events was 1 and 0 in a standard therapy group $(\mathrm{n}=111)$, respectively [17]. Recently, one report from Japan reported a nivolumab-related severe event of hypercalcemia in a patient with metastatic renal cell carcinoma [18]. Taken together, we speculate that the hypercalcemia experienced by our patient may have been due to either adrenal failure based on isolated ACTH deficiency or may have been a direct adverse event associated with nivolumab administration. As far as we know, this is the first case report in which the patient simultaneously developed both isolated ACTH deficiency and severe hypercalcemia after nivolumab therapy. Although both isolated ACTH deficiency and hypercalcemia can cause a disturbance of consciousness, since clinical symptoms including lethargy were relatively rapidly improved according to the decrease of serum $\mathrm{Ca}$ levels by the treatment for hypercalcemia, we speculate that hypercalcemia was the major cause of the disturbance in consciousness rather than the adrenal failure caused by the isolated ACTH deficiency.

In our case, hypothyroidism was noted with elevated TSH 1 week before the onset of the disturbance in consciousness with fatigue and a sensation of weakness. Although it is known that hypocortisolemia is associated with the elevation of circulating TSH levels [19], we speculate this elevated TSH was due to hypothyroidism based on destructive thyroiditis because the destructive thyroiditis had probably preceded the onset of isolated ACTH deficiency. In addition, hypothyroidism can also cause a disturbance of consciousness. However, because administration of levothyroxine was started immediately after the diagnosis of hypothyroidism (i.e., before the onset of the disturbance of consciousness), it is unlikely that hypothyroidism fully contributed to the disturbance of consciousness in this case. Finally, it is well known that hyperthyroidism can result in mild hypercalcemia. Although the dose of the administrated levothyroxine was low, it is possible that the levothyroxine enhanced the potential association between isolated ACTH deficiency and hypercalcemia as described above.

In conclusion, we treated a patient with a malignant melanoma metastasis in the liver who developed possible destruc- tive thyroiditis and had subsequently a simultaneous onset of isolated ACTH deficiency and severe hypercalcemia after nivolumab therapy. These possible side effects occurred even after withdrawal of the drug for more than 1 month. Both adrenal failure due to isolated ACTH deficiency and hypercalcemia can cause a disturbance of consciousness and can be lifethreatening side effects of nivolumab. Clinicians should pay careful attention to the possibility of these rare but important nivolumab side effects if the patients who received this drug develop a disturbance of consciousness.

\section{Conflict of Interest}

All authors have no conflict of interest to disclose.

\section{References}

1. Sznol M, Postow MA, Davies MJ, Pavlick AC, Plimack ER, Shaheen M, Veloski C, et al. Endocrine-related adverse events associated with immune checkpoint blockade and expert insights on their management. Cancer Treat Rev. 2017;58:70-76.

2. Kumar V, Chaudhary N, Garg M, Floudas CS, Soni P, Chandra AB. Current Diagnosis and Management of Immune Related Adverse Events (irAEs) Induced by Immune Checkpoint Inhibitor Therapy. Front Pharmacol. 2017;8:49.

3. Rizvi NA, Mazieres J, Planchard D, Stinchcombe TE, Dy GK, Antonia SJ, Horn L, et al. Activity and safety of nivolumab, an anti-PD-1 immune checkpoint inhibitor, for patients with advanced, refractory squamous non-small-cell lung cancer (CheckMate 063): a phase 2, single-arm trial. Lancet Oncol. 2015;16(3):257-265.

4. Topalian SL, Hodi FS, Brahmer JR, Gettinger SN, Smith DC, McDermott DF, Powderly JD, et al. Safety, activity, and immune correlates of anti-PD-1 antibody in cancer. N Engl J Med. 2012;366(26):2443-2454.

5. Weber JS, Postow M, Lao CD, Schadendorf D. Management of adverse events following treatment with anti-programmed death-1 agents. Oncologist. 2016;21(10):12301240.

6. Makarious D, Horwood K, Coward JIG. Myasthenia gravis: An emerging toxicity of immune checkpoint inhibitors. Eur J Cancer. 2017;82:128-136.

7. Hasegawa Y, Kawai S, Ota T, Tsukuda H, Fukuoka M. Myasthenia gravis induced by nivolumab in patients with non-small-cell lung cancer: a case report and literature review. Immunotherapy. 2017;9(9):701-707.

8. Takebayashi K, Aso Y, Tayama K, Takemura Y, Inukai T. Primary antiphospholipid syndrome associated with acute adrenal failure. Am J Med Sci. 2003;325(1):41-44.

9. OPDIVO ${ }^{\circledR}$ (nivolumab) Prescribing Information (Revised 10/2016) <http://packageinserts.bms.com/pi/pi_opdivo.pdf $>$ [accessed October 21, 2016].

10. Faje A. Immunotherapy and hypophysitis: clinical presentation, treatment, and biologic insights. Pituitary. 
2016;19(1):82-92.

11. Okano Y, Satoh T, Horiguchi K, Toyoda M, Osaki A, Matsumoto S, Tomaru T, et al. Nivolumab-induced hypophysitis in a patient with advanced malignant melanoma. Endocr J. 2016;63(10):905-912.

12. Kitajima K, Ashida K, Wada N, Suetsugu R, Takeichi Y, Sakamoto S, Uchi H, et al. Isolated ACTH deficiency probably induced by autoimmune-related mechanism evoked with nivolumab. Jpn J Clin Oncol. 2017;47(5):463-466.

13. Takaya K, Sonoda M, Fuchigami A, Hiyoshi T. Isolated Adrenocorticotropic Hormone Deficiency Caused by Nivolumab in a Patient with Metastatic Lung Cancer. Intern Med. 2017;56(18):2463-2469.

14. Faje A. Hypophysitis: evaluation and management. Clin Diabetes Endocrinol. 2016;2:15.

15. Wong RK, Gregory R, Lo TC. A case of isolated ACTH deficiency presenting with hypercalcaemia. Int J Clin Pract. 2000;54(9):623-624.

16. Jacobs TP, Bilezikian JP. Clinical review: Rare causes of hypercalcemia. J Clin Endocrinol Metab. 2005;90(11):6316-6322.

17. Ferris RL, Blumenschein G, Jr., Fayette J, Guigay J, Colevas AD, Licitra L, Harrington K, et al. Nivolumab for recurrent squamous-cell carcinoma of the head and neck. N Engl J Med. 2016;375(19):1856-1867.

18. Kobari Y, Kondo T, Takagi T, Omae K, Nakazawa H, Tanabe K. Rapid progressive disease after nivolumab therapy in three patients with metastatic renal cell carcinoma. In Vivo. 2017;31(4):769-771.

19. Hannon MJ, O'Halloran DJ. Isolated acquired ACTH deficiency and primary hypothyroidism: a short series and review. Pituitary. 2011;14(4):358-361. 